\section{A Novel System for Reducing Leaching from Formulations of Anionic Herbicides: Clay-Liposomes}

TOMAS UNDABEYTIA, *, † YAEL GOLDA MISHAEL $\neq$ SHLOMO NIR, $B$ RIGITTE PAPAHADJ OPOULOS-STERNBERG, § BARUCH RUBIN, ${ }^{\ddagger}$ ESMERALDA MORILLO, ${ }^{\dagger}$ AND CELIA MAQUEDA

Institute of Natural Resources and Agrobiology, CSIC, Apdo 1052, 41080 Sevilla, Spain, Faculty of Agricultural, Food and Environmental Quality Sciences, Hebrew University of Jerusalem, Rehovot 76100, Israel, and Nano Analytical Laboratory, San Francisco, California 94118

A new approach was developed for reducing leaching of herbicides and contamination of groundwater. Liposomeclay formulations of the anionic herbicides sulfometuron and sulfosulfuron were designed for slow release by incorporating the herbicide in positively charged vesicles of didodecyldimethylammonium (DDAB), which were adsorbed on the negatively charged clay, montmorillonite. Freeze fracture electron microscopy demonstrated the existence of DDAB vesicles and aggregated structures on external clay surfaces. X-ray diffraction results for DDAB with montmorillonite imply the existence of DDAB bilayers with an oblique orientation to the basal plane within the clay interlayer space at adsorbed amounts beyond the cation exchange capacity of the clay. Adding DDAB with sulfometuron or sulfosulfuron to montmorillonite yielded $95 \%$ or $83 \%$ adsorption of the herbicide at optimal ratios. Liposome-clay formulations exhibited slow release of the herbicides in water. Analytical measurements in soil columns demonstrated $2-10$-fold reduction in leaching of the herbicides from liposome-clay formulations in comparison with commercial formulations. Percents of root growth inhibition of a test plant in the upper soil depths were severalfold higher for the liposome-clay formulations than for the commercial ones. Consequently, liposomeclay formulations of anionic herbicides can solve environmental and economical problems by reducing their leaching.

\section{Introduction}

Herbicide mobilityin soils has long been of concern for many reasons, including the following (1): (i) contamination of groundwater; (ii) a reduction in efficacy due to herbicide leaching below the weed seed zone, which can harm the treated crop; and (iii) surfacemigration of the herbicide which harms neighboring crops.

Groundwater contamination resulting from herbicide leaching has been observed in major agricultural regions ( 2 ,

* Corresponding author phone: +34-954624711; fax: +34954624002; e-mail: undabeyt@irnase.csic.es.

+ Institute of Natural Resources and Agrobiology, CSIC.

‡ Hebrew University of Jerusalem.

$\S$ Nano Analytical Laboratory.
3). Several strategies have been considered for preventing herbicide leaching, such as adapting appropriate crop management practices, modifying application techniques, and developing slow release formulations $(4,5)$.

A number of processes for coating or microencapsulating pesticides have been developed in the past decade (6-12): interfacial polymerization (6); complex coacervation (7): annular-jet encapsulation (8); cellulose coating (9); al ginate gelling process (10); and trapping in cyclodextrins (11).

Sulfonylureas are weakly acidic herbicides with high bioactivity at low doses, which are employed in pre- and postemergence for control of a wide range of grass and broadleaved weeds in crops and in nonfarm conditions (13). Although thesenew herbicides are applied at low rates, their potential for mobility, especially in basic soils, poses a hazard (14)

The current study demonstrates the use of a liposomeclay system as a new tool for designing slow release formulations of sulfonylurea and other anionic herbicides. The approach used consists of incorporating the herbicide in positively charged vesicles of quaternary amine cations, which adsorb on a negatively charged clay mineral, such as montmorillonite. Didodecyldimethylammonium bromide (DDAB) and two sulfonylurea herbicides (sulfometuron and sulfosulfuron) were chosen for this study. The results of this study show that the combination of vesicles and clay particles slows down the rate of herbicide release and consequently reduces leaching.

\section{Experimental Section}

Materials. Didodecyldimethylammonium bromide(DDAB) was supplied by Aldrich Chemical Co. (Milwaukee, WI). Sulfometuron, 2-[3-4, 6-dimethylpyrimidin-2-yl ureidosulfonyl]benzoic acid (analytical grade, $\mathrm{pK}_{\mathrm{a}}=5.2$ ) (SFM) and commercial (OUST), and sulfosulfuron 1-(4,6-dimethylpyrimidin-2-yl)-3-(2-ethylsulfonylimidazo[1,2-a]pyridin 3-yl (analytical grade, $\mathrm{pK}_{\mathrm{a}}=3.5$ ) (SFS) and commercial (MONITOR) were provided by E.I. Dupont de Nemours \& Company (Wilmington, DE). The a.i. content of the herbicide in both commercial formulations was $75 \%$. The structural formulas of the herbicides and DDAB are shown in Figure 1. The clay used was aWyoming montmorillonite(SWy-2) obtained from the Source Clays Repository of The Clay Minerals Society (Columbia, MO), whose cationic exchange capacity (CEC) was $0.82 \mathrm{mmol} / \mathrm{g}$. Sodium tetraborate -10-hydrate, trifluoroacetic acid, and HPLC acetonitrile were purchased from Sigma-Aldrich (Sigma Chemical Co., St. Louis, MO).

The upper horizon of a sandy soil ( $~ 90 \%$ sand) from Coria (Sevilla, Spain) with a 6.9\% carbonate content and a basic $\mathrm{pH}$ (8.0) was passed through a $2 \mathrm{~mm}$ sieve before use.

\section{Methods}

Vesicle Preparation. Lipid vesicles of DDAB were prepared by first dissolving the lipid in ethanol and then diluting with water at a ratio of 1:100. A subsequent sonication of thelipid solutions was performed for $1 \mathrm{~h}$ to ensure size homogeneity of the formed vesicles.

Adsorption of Liposomes on Montmorillonite. Adsorption of DDAB on the clay was carried out in duplicate in borosilicate tubes by mixing $10 \mathrm{~mL}$ of lipid solutions whose concentrations ranged up to $9 \mathrm{mM}$, with $5 \mathrm{~mL}$ of clay suspension under continuous stirring. The final clay concentration in the tubes was $1.6 \mathrm{~g} / \mathrm{L}$. After shaking for 3 days at $20{ }^{\circ} \mathrm{C}$, the tubes were centrifuged at $20000 \mathrm{~g}$ for $20 \mathrm{~min}$, the supernatants were discarded, and the pellets were freeze- 

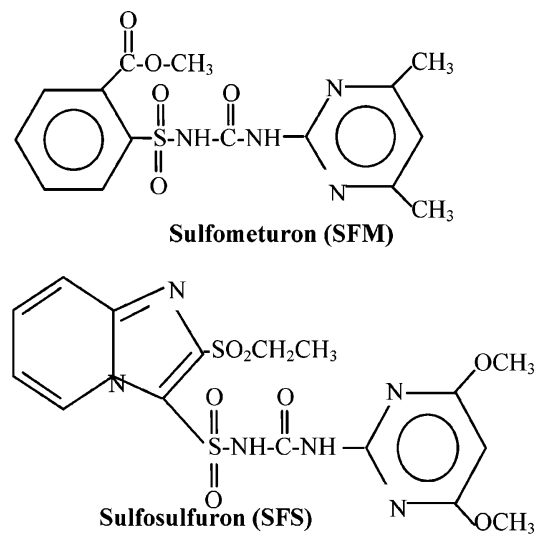

$\left[\mathrm{CH}_{3}\left(\mathrm{CH}_{2}\right)_{11}\right]_{2} \mathrm{~N}\left(\mathrm{CH}_{3}\right)_{2} \mathrm{Br}$ Didodecyldimethylammonium bromide (DDAB) FIGURE 1. Structural formulas of the molecules used.

dried. The content of DDAB in the pellet was determined by using a CNHSO analyzer type Carlo-Erba 1108.

$X$-ray Diffraction. X-ray diffraction of oriented samples on glass slides was measured using a Siemens D-5000 X-ray diffractometer with $\mathrm{Ni}$-filtered $\mathrm{CuK} \alpha$ radiation. The samples were prepared from the paste obtained after centrifugation of the lipid-clay suspensions of the adsorption experiments.

Freeze-FractureElectron Microscopy. For freeze-fracture electron microscopy samples of DDAB, montmorillonite, and DDAB adsorbed on montmorillonite were quenched using sandwich technique and liquid nitrogen cooled propane. Applying this technique, shock freezing of the samples was performed at a cooling rate of about 10000 degrees per second suppressing any ice-crystal-related artifact formation (15). The exposed fracture planes were shadowed with platinum for $30 \mathrm{~s}$ at an angle of 25-35 degrees and with carbon for $35 \mathrm{~s}\left(2 \mathrm{kV} / 60-70 \mathrm{~mA}, 1 \times 10^{-5}\right.$ Torr) using a freezeetching device JEOLJFD-9000. Thereplicas produced bythis technique were cleaned with concentrated fuming $\mathrm{HNO}_{3}$ for 24-36 $\mathrm{h}$ and examined with a transmission electron microscope JEOL 100CX.

Binding of Sulfometuron (SFM) and Sulfosulfuron (SFS) to Liposomes. DDAB was dissolved in ethanol, followed by a 100-fold dilution with a solution of SFM or SFS prepared in a borate/ $\mathrm{HCl}$ buffer whose $\mathrm{pH}$ was 8.5. The buffer consisted of a (70:30\%, v:v) mixture of a $0.05 \mathrm{M}$ Borax solution and a $0.1 \mathrm{M} \mathrm{HCl}$ solution, respectively. These vesicle suspensions were sonicated for $1 \mathrm{~h}$.

The amount of SFM or SFS bound to vesicles was determined by dialyzing $20 \mathrm{~mL}$ of SFM-lipid solutions in dialysis bags (MWCO: 1000) supplied by Spectrum Lab. (Breda, The Netherlands), versus $40 \mathrm{~mL}$ of buffer medium in closed glass beakers. After shaking for 3 days at $20^{\circ} \mathrm{C}$, herbicideconcentrations insideand outsidethedialysis bags were determined, and their bound amounts were calculated. The herbicides were analyzed by HPLC (Merck Hitachi 6200, Tokyo, Japan) equipped with PDA detector set at a wavelength of $232 \mathrm{~nm}$ for SFM and $216 \mathrm{~nm}$ for SFS. A reverse phase column LiChrospher 100 RP-18 (5 $\mu \mathrm{M}$ ) (Merck, Darmstadt, Germany) was used. The mobile phase was a mixture of $70 \%$ acetonitrileand $30 \%$ water solution of $0.65 \mathrm{mM}$ trifluoroacetic

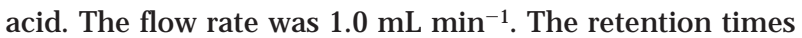
were $8.7 \mathrm{~min}$ for SFM and $14.2 \mathrm{~min}$ for SFS.

Adsorption of SFM and SFS on Liposome-Clays. Adsorption of both herbicides on montmorillonite-liposome systems as well as their speciation in solution was determined in duplicate by using dialysis experiments as in the previous section. Montmorillonite was added inside the dialysis bags containing $20 \mathrm{~mL}$ of SFM- , or SFS-vesicle suspensions, which were dialyzed versus $40 \mathrm{~mL}$ of buffer in closed glass beakers. The clay concentration ranged from 1.6 to $10 \mathrm{~g} / \mathrm{L}$. After shaking for 3 days at $20^{\circ} \mathrm{C}$, the same procedure as above was used for determination of herbicideconcentrations. A parallel experiment was done by adding the clay mineral outsidethe dialysis bag.

Release Experiments. Adsorption of the vesicles on the clay for 3 days was performed in borosilicatetubes by adding vesicle suspensions containing the herbicides to montmorillonite, at 1.6 and $3.5 \mathrm{~g} / \mathrm{L}$ clay concentrations. Desorption of the herbicides from the clay-liposome systems was performed by replacing the supernatant with borate buffer after letting the suspensions equilibrate for an additional period of 3 days.

In addition, DDAB release from the clay was also studied by adsorbingthelipid on montmorillonite at a surfaceloading below and beyond the CEC and replacing the supernatant by $100 \mathrm{mM}$ solutions of $\mathrm{NaCl}$ and $\mathrm{CsCl}$.

Leaching Experiments. Formulations were prepared by mixing a 0.6:6 mM herbicide:DDAB solution with montmorillonite at 1.6, 3.6, and $5 \mathrm{~g} / \mathrm{L}$ clay. Incubation proceeded for 3 days to reach equilibration; and then freeze-drying was applied after removing the supernatant by centrifugation. These formulations are denoted as $1.6,3.6$, and $5 \mathrm{~g} / \mathrm{L}$ formulations, respectively. Commercial formulations of SFM (OUST) and SFS (MONITOR) were also used.

Metacrylate tubes of $3.0 \mathrm{~cm}$ diameter were cut into 4 - and $8-\mathrm{cm}$ sections, and five units of $4 \mathrm{~cm}$ were glued together with a $8 \mathrm{~cm}$ unit at one end to construct a $28 \mathrm{~cm}$ column. The column was covered at theend opposite to the $8 \mathrm{~cm}$ unit with $1 \mathrm{~mm}$ nylon screen padded with a thin layer of glass wool $(0.5 \mathrm{~g})$ to hold the soil firmly in the column. Soil $(0.246$ $\mathrm{kg}$ ) was packed from the top of the column ( $8 \mathrm{~cm}$ section), creating a $24 \mathrm{~cm}$ soil column that could be readily separated into $4 \mathrm{~cm}$ segments. A thin layer of glass wool was placed on top of each soil column to maintain theintegrity of the surface during leaching.

The pore volume was determined to be $57 \mathrm{~mL}$ as in ref 16. The columns were treated with 5 pore volumes of a 0.01 $\mathrm{M} \mathrm{Ca}\left(\mathrm{NO}_{3}\right)_{2}$ solution followed by 1 pore volume of distilled water beforespraying $10 \mathrm{~mL}$ of suspensions of thecommercial and DDAB formulations of SFM and SFS at a rate of $420 \mathrm{~g}$ a.i. ha ${ }^{-1}$. Distilled water equivalent to half pore volume of the soil column was added every $24 \mathrm{~h}$ during 11 days at the top of the column, and the leachates were collected and analyzed for the herbicide.

Each soil column was separated into six $4 \mathrm{~cm}$-segments, and the soil was dried at $40{ }^{\circ} \mathrm{C}$. A bioassay was used to calculate the residual activity of the herbicides throughout the first two upper rings of the soil column by measuring the inhibition of root growth of sorghum seedlings. Soil (5 g) from each segment was mixed with $60 \mathrm{~g}$ of sand and kept after addition of $14 \mathrm{~mL}$ of water in darkness in Petri dishes, where 9 seeds of sorghum were planted. The Petri dishes were kept tilted at an angle of $60^{\circ}$, and the elongation of the seedlings was measured after 9 days. The inhibition percent was calculated as the reduction in the elongation of the roots of seedlings in comparison with those grown in nontreated soil.

Another parallel experiment was performed with the herbicide SFS, where a dose of $35 \mathrm{~g}$ a.i. ha ${ }^{-1}$ was used, and after irrigation with 1 pore volume the column was sliced and the same procedureas before was repeated to determine theherbicidal activity in the first two rings of thesoil columns.

\section{Results and Discussion}

Adsorption of Liposomeson Montmorillonite. (i) Adsorption Isotherms. The adsorption isotherm of DDAB on montmorillonite is shown in Figure 2. DDAB shows a high affinity for montmorillonite reaching an adsorption plateau at about $1.5 \mathrm{mmol} / \mathrm{g}$, amounting to almost twice the CEC $(0.8$ $\mathrm{mmol} / \mathrm{g})$. 


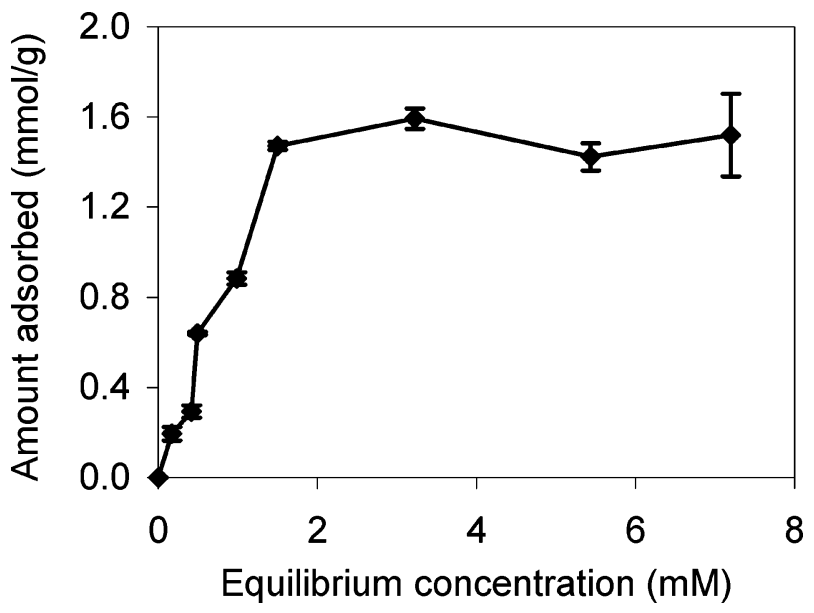

FIGURE 2. Adsorption isotherm of DDAB on montmorillonite (1.6 g/L).

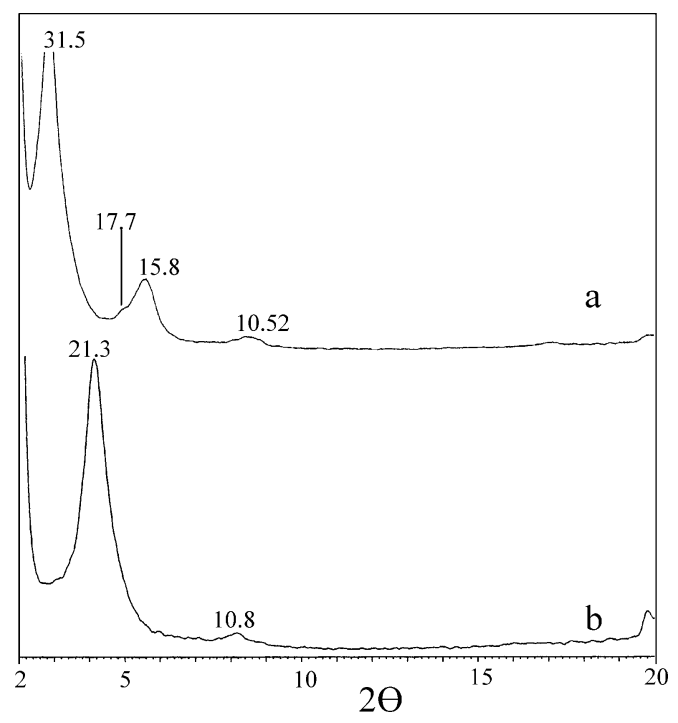

FIGURE 3. X-ray diffraction of (a) $6 \mathrm{mM}$ of DDAB added to $1.6 \mathrm{~g} / \mathrm{L}$ clay and (b) $6 \mathrm{mM}$ of DDAB added to $10 \mathrm{~g} / \mathrm{L}$.

Svitova et al. (17) determined a critical vesicle concentration (CVC) corresponding to the transition from molecular to vesicular solutions at $3.5 \times 10^{-5} \mathrm{M}$ for DDAB, and lamellar phases are formed at higher concentrations (>9 mM) (18). Consequently, DDAB remains in solution practically as vesicles.

(ii) X-ray Diffraction (XRD). Figure 3 shows XRD measurements undertaken on montmorillonite treated with vesicular suspensions of DDAB. The basal spacing of untreated montmorillonite is $14.8 \AA$, indicating a bilayer of water molecules present between thesilicatelayers (19). Clay $(1.6 \mathrm{~g} / \mathrm{L})$ treated with 0.3 and $0.6 \mathrm{mM}$ solutions of DDAB produced a shift of the basal spacing from 13.4 to $16.3 \AA$ (not shown). A basal spacing of $13.4 \AA$ indicates partial dehydration of the clay surface and adsorption of the organic cation as monomers, whereas a value of $16.3 \AA$ may imply adsorption of a large fraction (58\%) of the organic molecules as bilayers parallel to the clay surface (20). In Figure $3 a$, the clay was treated with a higher initial concentration of DDAB $(6 \mathrm{mM})$ for the same clay concentration, where DDAB adsorption exceeds the CEC by about twice $(1.5 \mathrm{mmol} / \mathrm{g}$, Figure 2$)$. A series of diffraction peaks can be ascribed to different orders of a basal spacing of $31.5 \AA$. In addition, a very small peak at $17.7 \AA$ indicative of adsorption as bilayers of DDAB molecules lying parallel to the clay surface is noted. A similar pattern was noted by Tahani et al. (21) for the adsorption of

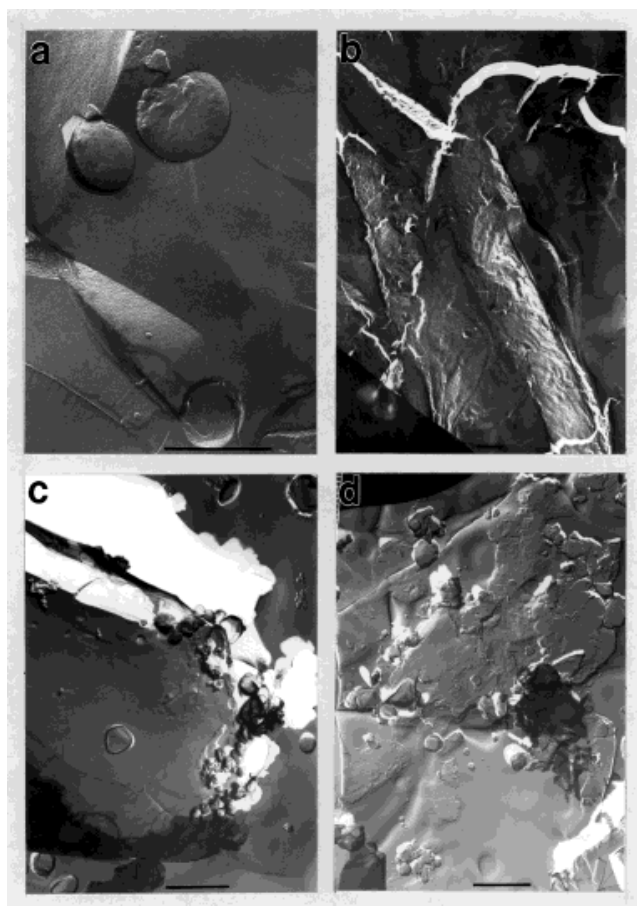

FIGURE 4. Freeze-fracture electron micrographs of liposome control (DDAB $3 \mathrm{mM}$ ) (a); clay control (3.2 g montmorillonite/L) (b); liposome/clay interaction after 5 min incubation time (c); and liposome/clay interaction as in (c) but after $85 \mathrm{~min}$ incubation time (d). The bars in (a) and (c) represent $0.5 \mu \mathrm{m}$ and in (b) and (d) $1 \mu \mathrm{m}$. Shadow direction is running from bottom to top on all electron micrographs.

the organic cation benzyldimethyldodecylammonium (BDDA) on montmorillonite, where values of 34 and $18 \AA$ were reported. These authors studied BDDA adsorption on the clay at loads below and beyond the CEC and concluded that the organic cation was forming bilayers parallel to the clay surface at a loading below the CEC, and a second interlamellar distance of $34 \AA$ appeared at 1.38 of the CEC and remained constant for higher loading. Theexcess of adsorbed surfactant cations gave a rearrangement of the alkylchains to develop an interdigitated bilayer with an oblique orientation to the basal spacing and coexisting with bilayers parallel to the clay. Adsorption ofDDAB on theclay will produce a similar pattern when packed at a high loading on the clay, because of the similar areas per surfactant molecule in condensed monolayers reported for DDAB $\left(68 \AA^{2}\right)(22)$ and BDDA $\left(70.5 \AA^{2}\right)$ (21).

In Figure 3b, the X-ray diffraction pattern for $6 \mathrm{mM}$ DDAB is shown by using a higher clay concentration (10 $\mathrm{g} / \mathrm{L})$ than that used in Figure $3 a(1.6 \mathrm{~g} / \mathrm{L})$. In this case, the adsorbed amount is below the CEC $(0.8 \mathrm{mmol} / \mathrm{g})$, since DDAB was added at $0.6 \mathrm{mmol} / \mathrm{g}$ clay. A peak at $21.3 \AA$ is obtained instead, which is associated with a pseudotrimolecular layer arrangement of the organic cation. Jaynes and Vance (23) indicated a pseudotrimolecular layer conformation for DDAB adsorbed on montmorillonite just below the CEC. This arrangement will correspond to a transitional conformation, and at higher loading there will be a rearrangement of the alkyl chains of DDAB as in Figure 3a. As shown in the present study, the conformation adopted by the organic cation adsorbed in the interlayer space is dependent on the ratio between the organic cation and the clay.

(iii) Freeze-Fracture Electron Microscopy. The freezefracture micrographs of the liposome control showed DDAB vesicles in the size range of $150 \mathrm{~nm}$ to $1.35 \mu \mathrm{m}$, with a maximum around $300 \mathrm{~nm}$ (Figure 4a). The clay control 
TABLE 1. SFM Adsorption on Montmorillonite and Its Speciation in Solution in Vesicle-Clay Systems as a Function of Clay Concentration and for Several DDAB/SFM Ratios ${ }^{\text {a }}$

$\begin{array}{ccll}\begin{array}{c}\text { DDAB } \\ \text { concn } \\ \text { (mM) }\end{array} & \begin{array}{c}\text { SFM } \\ \text { concn } \\ \text { (mM) }\end{array} & \begin{array}{c}\text { clay } \\ \text { added } \\ \text { (g/L) }\end{array} \\ 3 & 0.2 & 0 \\ 3 & 0.3 & 0 \\ 6 & 0.3 & 0 \\ 6 & 0.3 & 5 \\ 6 & 0.6 & 0 \\ 6 & 0.6 & 1.6 \\ 6 & 0.6 & 2.5 \\ 6 & 0.6 & 3.6 \\ 6 & 0.6 & 5 \\ 6 & 0.6 & 6.5 \\ 6 & 0.6 & 10 \\ 6 & 0.6 & 1.6, \text { outside } \\ 6 & 0.6 & 5, \text { outside } \\ 6 & 0.6 & 10, \text { outside } \\ 6 & 1.2 & 0 \\ 6 & 1.2 & 1.6 \\ 8 & 0.8 & 1.6 \\ 8 & 0.8 & 3.6 \\ 18 & 0.8 & 0\end{array}$

\begin{tabular}{crc} 
& \multicolumn{2}{c}{ percentage in solution } \\
\cline { 2 - 3 } $\begin{array}{c}\text { percentage } \\
\text { adsorbed }\end{array}$ & $\begin{array}{c}\text { bound to } \\
\text { vesicles }\end{array}$ & $\begin{array}{c}\text { unbound to } \\
\text { vesicles }\end{array}$ \\
& $63.0 \pm 0.6$ & $37.0 \pm 0.6$ \\
& $41.1 \pm 1.7$ & $58.9 \pm 1.7$ \\
& $70.7 \pm 0.7$ & $29.3 \pm 0.7$ \\
$95.2 \pm 0.3$ & $0 \pm 0.6$ & $4.8 \pm 0.6$ \\
& $62.7 \pm 3.2$ & $36 \pm 3.2$ \\
$59.1 \pm 2.4$ & $18.5 \pm 2.5$ & $22.4 \pm 4.2$ \\
$75.9 \pm 0.9$ & $5.4 \pm 5.7$ & $18.7 \pm 4.8$ \\
$85.4 \pm 0.3$ & $1.7 \pm 1.3$ & $12.8 \pm 1.0$ \\
$91.9 \pm 0.4$ & $0 \pm 0.1$ & $8.0 \pm 0.4$ \\
$85.9 \pm 0.4$ & $0.5 \pm 0.1$ & $13.6 \pm 0.5$ \\
$67.9 \pm 1.9$ & $0.8 \pm 2.0$ & $31.3 \pm 3.3$ \\
$8.2 \pm 1.8$ & $58.7 \pm 9.0$ & $33.1 \pm 10.9$ \\
$8.9 \pm 2.0$ & $48.9 \pm 4.3$ & $42.2 \pm 5.6$ \\
$6.4 \pm 1.2$ & $54.6 \pm 2.1$ & $39.0 \pm 2.5$ \\
& $9.7 \pm 0.5$ & $90.3 \pm 0.5$ \\
$22.8 \pm 4.7$ & $47.0 \pm 7.9$ & $30.1 \pm 3.2$ \\
$40.7 \pm 4.9$ & $8.4 \pm 4.7$ & $50.8 \pm 0.2$ \\
$76.6 \pm 0.2$ & $2.4 \pm 0.1$ & $20.9 \pm 0.2$ \\
& $87.0 \pm 5.3$ & $13.0 \pm 5.3$
\end{tabular}

a In some cases, the clay was added outside the dialysis bags.

sample in Figure $4 \mathrm{~b}$ displayed well-defined sharp edge clods with edge lengths of about 8-20 $\mu \mathrm{m}$, as in ref 19.

The short time incubation ( $5 \mathrm{~min}$ ) of the liposomes with the clay revealed new small clods (up to $6 \mu \mathrm{m}$ ) arising from aggregation of vesicles on the clay surface (Figure 4c). This vesicle aggregation was not observed after preparation in the liposome control.

By increasing the incubation time up to $85 \mathrm{~min}$, the clay clods are fairly larger showing a length of $\sim 11 \mu \mathrm{m}$. Furthermore, there is a deformation of the vesicles by developing an extended bilayer area on the clay surface. The deformation rate of the liposomes is influenced by two factors: the electrostatic attraction between the liposomes and the clay plates and the collision rate of the adsorbing vesicles (24). The relative importance of both factors will depend on the relative concentration of clay particles and vesicles. Regev and Khan (25) studied DDAB transitions with an increase in the lipid concentration and observed vesicles and tubules in equilibrium beforea lamellar phase was formed. In this case, the concentration of vesicles on the clay surface is high enough to develop a bilayer on the clay surface (26). These surface transformations occur over a period of hours (27).

Binding of SFM and SFS to Liposomes. The results in Table 1 indicate that a significant fraction of the anionic herbicide SFM can bind to DDAB vesicles in the absence of the clay. Fractions of SFS bound were somewhat smaller (see TableS1 in Supporting Information). An increase in the concentration of the herbicides for the same DDAB concentration produced a decrease in SFM and SFS binding to DDAB vesicles, which is due to a reduction in the lipid/ herbicide ratio.

A rough estimation of the affinity of the herbicide molecules to the vesicles was obtained by fitting the results to the Scatchard equation which is equivalent to that of Langmuir (28), by assuming that each DDAB molecule can mostly bind one herbicide molecule. The binding coefficients provide a convenient scale for comparison, rather than absolute values of the changes of the free energy upon adsorption (29). The binding coefficients obtained were 800 $\mathrm{M}^{-1}$ and $120 \mathrm{M}^{-1}$ for SFM and SFS binding, respectively. The fit was very good for SFM $\left(R^{2}=0.998\right)$ and fair for SFS $\left(R^{2}\right.$ $=0.88$ ).
Adsorption and Speciation of SFM and SFS on Montmorillonitein thePresence of Liposomes. Results of dialysis experiments where DDAB liposomes and SFM were added together with the clay mineral are shown in Table 1 . The percentages of SFM and SFS (Table S1 in Supporting Information) adsorbed on montmorillonite increased when increasing the clay concentration up to $5 \mathrm{~g} / \mathrm{L}$, with a concomitant decrease in both the percent bound to vesicles and that remaining as unbound to vesicles in solution. Since both herbicides did not adsorb per se on the clay, this trend may indicate that the incorporation of both herbicides in vesicles was essential for their adsorption on the clay mineral.

An additional experiment testing the adsorption of the herbicide on the clay via incorporation in vesicles was performed by employing a dialysis bag where the vesicles were added in the interior, whereas the clay was added outside. When the dialysis bags contained $6 \mathrm{mM}$ DDAB and $0.6 \mathrm{mM}$ SFM, the fractions of herbicides adsorbed on the clay dropped to $6-9 \%$, in comparison to the addition of the clayinside(59-92\%), whereas the percents bound to vesicles and in solution increased appreciably. This indicates that the adsorption of SFM on the clay mostly occurred through SFM incorporation in DDAB vesicles, which interacted with the mineral surface. When the vesicles were accessibleto the clay mineral surface, theadsorbed amounts of both herbicides increased significantly. The low percent of SFM adsorbed on the clay outside the dialysis bag could arise from a modification of the clay surface dueto adsorption of DDAB monomers. By using a range of CVC values between $3.5 \times 10^{-5}-4.75 \times$ $10^{-5} \mathrm{M}(17,18)$, the range of DDAB monomers comprises a small fraction of the adsorption sites of the clay. A similar trend was observed with SFS (Table S1 in Supporting Information).

When the clay was added inside the dialysis bags, the adsorbed percents of SFM were higher than expected from the sum of its percent binding to vesicles and percent adsorbed on the clay outside the dialysis bag. We deduce that adsorption of the vesicles on the clay which results in big aggregation (Figure 4) significantly promotes herbicide adsorption.

Table 1 exhibits maximal adsorbed amounts of SFM at a clay concentration of $5 \mathrm{~g} / \mathrm{L}$ and DDAB concentration of 6 $\mathrm{mM}$. A further increase in the concentration of the clay resulted in a reduction in the adsorbed fractions of the herbicidesand also in insignificant herbicide binding to vesiclesin solution. Our interpretation is that as the concentration of the clay increases beyond $5 \mathrm{~g} / \mathrm{L}$ the adsorption of DDAB monomers results in a certain degree of vesicle decomposition, which results in a smaller fraction of herbicide binding to the vesicles and subsequently in a smaller fraction of herbicide adsorption on the vesicle-clay particles. The XRD results (Figure3) indicatethat high clay concentration relative to that of DDAB promotes another arrangement of DDAB adsorbed on the clay, as can be seen by a comparison of part a with part $b$ of Figure 3.

The results in Table 1 demonstrate that maximal adsorption of SFM on the clay surface occurs at optimal ratios between the concentrations of herbicide, lipid, and clay.

Release Experiments. The percentages of SFM and SFS released from DDAB-montmorillonite are shown in Table 2. The release percentages of SFM and SFS ranged from 4.4 to $20.0 \%$ and from 3.8 to $12.2 \%$ for SFM and SFS, respectively, indicating a relatively low released fraction of the herbicides, in particular for the $5 \mathrm{~g} / \mathrm{L}$ clay suspension and low herbicide loading. At the same clay concentration used, the released percentages were lower for the herbicide SFS than for SFM.

The release of DDAB from montmorillonite was followed by studying the effect of the background electrolyte on the amounts of DDAB remaining adsorbed on the clay (Table 3 ). Theionic strength used was $0.1 \mathrm{M}$, since higher ionic strengths 
TABLE 2. Percentages of SFM and SFS Released from Vesicle-Clay Formulations as a Function of Clay Concentration $^{\mathrm{a}}$

$\begin{array}{cccc}\text { herbicide } & \begin{array}{c}\text { clay concn } \\ \mathbf{( g / L )}\end{array} & \begin{array}{c}\text { loading } \\ (\mathbf{m m o l} / \mathbf{g})\end{array} & \begin{array}{c}\text { herbicide desorbed } \\ (\%)\end{array} \\ \text { SFM } & 1.6 & 0.22 & 20.0 \pm 2.8 \\ \text { SFM } & 3.6 & 0.14 & 9.5 \pm 0.3 \\ \text { SFM } & 5.0 & 0.11 & 4.4 \pm 0.1 \\ \text { SFS } & 1.6 & 0.20 & 12.2 \pm 0.7 \\ \text { SFS } & 3.6 & 0.13 & 5.6 \pm 0.2 \\ \text { SFS } & 5 & 0.10 & 3.8 \pm 0.1\end{array}$

${ }^{a}$ The initial concentrations of DDAB and herbicides were 6 and 0.6 $\mathrm{mM}$, respectively.

TABLE 3. Effect of $\mathrm{Na}^{+}$and $\mathrm{Cs}^{+}$on DDAB Release from Montmorillonite ${ }^{\mathrm{a}}$

$\begin{array}{ccc}\begin{array}{c}\text { DDAB adsorbed } \\ \text { (mmol/g) }\end{array} & \begin{array}{c}\text { salt } \\ \text { added }\end{array} & \begin{array}{c}\text { DDAB remaining } \\ \text { adsorbed (mmol/g) }\end{array} \\ 0.67( \pm 0.01) & \mathrm{NaCl} & 0.68( \pm 0.01) \\ & \mathrm{CsCl} & 0.59( \pm 0.07) \\ 1.70( \pm 0.02) & \mathrm{NaCl} & 1.51( \pm 0.03) \\ & \mathrm{CsCl} & 1.40( \pm 0.09)\end{array}$

${ }^{a}$ The clay concentration was $1.6 \mathrm{~g} \mathrm{~L}^{-1}$ and the ionic strength was $0.1 \mathrm{M}$

are unrealistic for most of the soil systems and can only be reached in extreme cases, such as less weathered soils from temperate climates or near fertilizer granules (30).

At loading below the CEC $(0.67 \mathrm{mmol} / \mathrm{g})$, the reduction in the amounts of DDAB adsorbed by using $\mathrm{CsCl}$ was about $12.5 \%$, whereas no reduction was observed by using $\mathrm{NaCl}$. This is related to the higher affinity of montmorillonite for $\mathrm{Cs}$ in comparison to $\mathrm{Na}$, the binding coefficients being 200 $\mathrm{M}^{-1}$ and $1 \mathrm{M}^{-1}$ for $\mathrm{Cs}$ and $\mathrm{Na}$, respectively (31). The stronger competition exerted by $\mathrm{Cs}$ will reduce the amounts of DDAB remaining adsorbed, but it may be noted that Cs concentration was 100-fold above that of DDAB.

In the presence of $0.1 \mathrm{M} \mathrm{NaCl}$, at adsorbed amounts of DDAB exceeding the CEC $(1.7 \mathrm{mmol} / \mathrm{g})$, its adsorption was reduced by $11.8 \%$. Polubesova et al. (32) also reported a decrease in the adsorbed amounts of the organic cations BTMA and BTEA on montmorillonite with an increase in the ionic strength. A similar pattern was described for the adsorption of the organic cation HDTMA on a subsoil containing vermiculite (33).

Hence the released amount of DDAB is not expected to cause a serious hazard, since the amounts released are only a small fraction of the applied, which would be very small.

Leaching Experiments. The breakthrough curves of the commercial and clay-based formulations of SFM and SFS on Coria soil are shown in Figure 5. The dose used for SFS is higher than that permitted for its use under field conditions, but the purpose was to compare the leaching potential of the formulations. The total recoveries of SFM and SFS from their commercial formulations amount to $95.0 \pm 4.7 \%$ and 93. $6 \pm 5.4 \%$ of the total applied, respectively. These values are in agreement with previous studies indicating low adsorption of sulfonylureas in most of agricultural soils, due to their presence as ionic forms at $\mathrm{pH}>6$ and their minimal adsorption on soil colloids (34).

In the case of SFM formulations, the cumulativeamounts of SFM eluted at the elution peak (1.5 pore volumes) which is equivalent to $121 \mathrm{~mm}$ of rain were $78.7 \pm 0.6 \%$ for the commercial formulation and $40.4 \pm 3.2 \%, 19.2 \pm 2.3 \%$, and $7.2 \pm 1.4 \%$ for the $1.6,3.6$, and $5 \mathrm{~g} / \mathrm{L}$ formulations, respectively, amounting to a significant reduction in leaching in the case of the clay-based formulations. After an addition of 5 pore
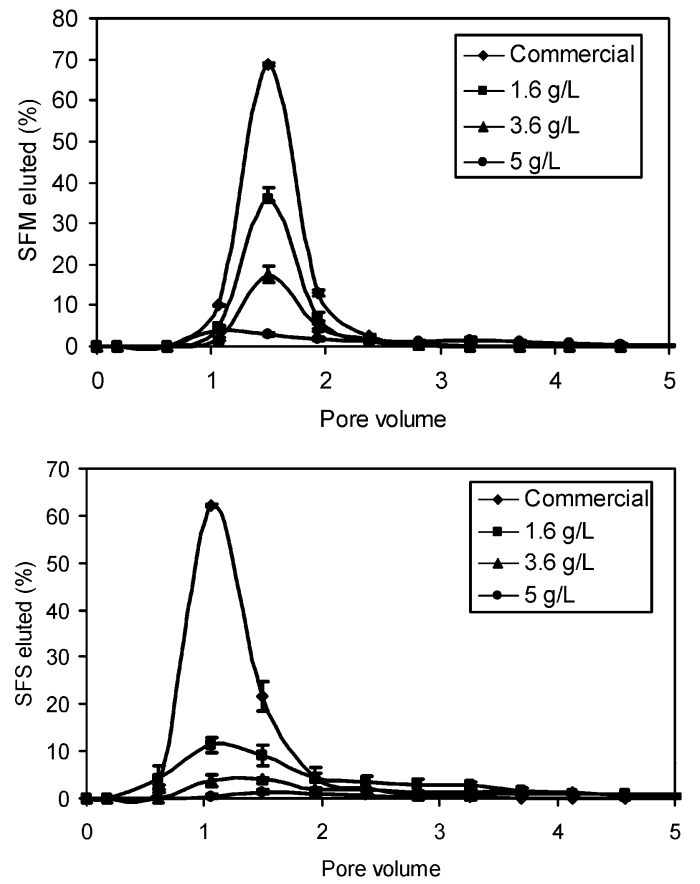

FIGURE 5. Elution curves of sulfometuron and sulfosulfuron in soil columns sprayed with the commercial formulations of these herbicides (w hose respective registered trade names are OUST for SFM and M ONITOR for SFS) and clay-liposome formulations of both herbicides prepared at several clay concentrations. The initial concentrations of DDAB and the herbicides were 6 and $0.6 \mathrm{mM}$, respectively. The rate used was $420 \mathrm{~g}$ a.i. ha ${ }^{-1}$.

volumes ( $403 \mathrm{~mm}$ of rain), where al most complete leaching of the commercial formulation occurred $(95.0 \pm 2.0 \%)$, the total leaching percents from the clay-based SFM formulations were $49.0 \pm 4.2 \%, 26.0 \pm 3.7 \%$, and $15.6 \pm 2.5 \%$ for the 1.6 , 3.6, and $5 \mathrm{~g} / \mathrm{L}$ formulations, respectively.

The clay-based formulations also reduced considerably the amount of SFS eluted. After 5 pore volumes the total leaching percents were $93.6 \pm 5.4 \%$ for the commercial formulation, whereas values of $41.7 \pm 5.3,17.7 \pm 2.4$, and 7.9 $\pm 2.0 \%$ were obtained for the $1.6,3.6$, and $5 \mathrm{~g} / \mathrm{L}$ clay-based formulations, respectively. Again, the $5 \mathrm{~g} / \mathrm{L}$ formulation yielded an order of magnitude reduction in the leached amount of the herbicide.

The total eluted percents of SFM are slightly higher than those of SFS for the same clay concentration. These results are in agreement with those for the release in water from the formulations (Table 2).

The herbicidal activity at the top layer of the soil column $(0-8 \mathrm{~cm})$ was tested by measuring theroot growth inhibition of sorghum seeds (Figure 6). The herbicidal activity was very low for the commercial formulation of SFM, just 3.4 and $6.5 \%$ for the $0-4$ and $4-8 \mathrm{~cm}$ layers, respectively. The herbicidal activity was 6-10 times higher for the 1.6 and 5 $\mathrm{g} / \mathrm{L}$ clay-liposome formulations at the upper layer. Statistically there was no difference between the herbicidal activity of formulations based on the two highest clay concentrations. Although the herbicidal activity was lower at the following layer $(4-8 \mathrm{~cm})$, where weed seeds can still germinate, the inhibition percentages were 2-fold higher for the clayliposome formulations than for thecommercial formulation.

The results of the herbicidal activity of SFS formulations at the top soil layers are remarkable. The two clay-liposome formulations tested had inhibition percentages between 35 and $40 \%$ in the first $4 \mathrm{~cm}$, whereas the commercial formulation did not show any activity. Because the soil columns were excessively irrigated with 5 pore volumes, another experiment was designed to compare the efficacy between 

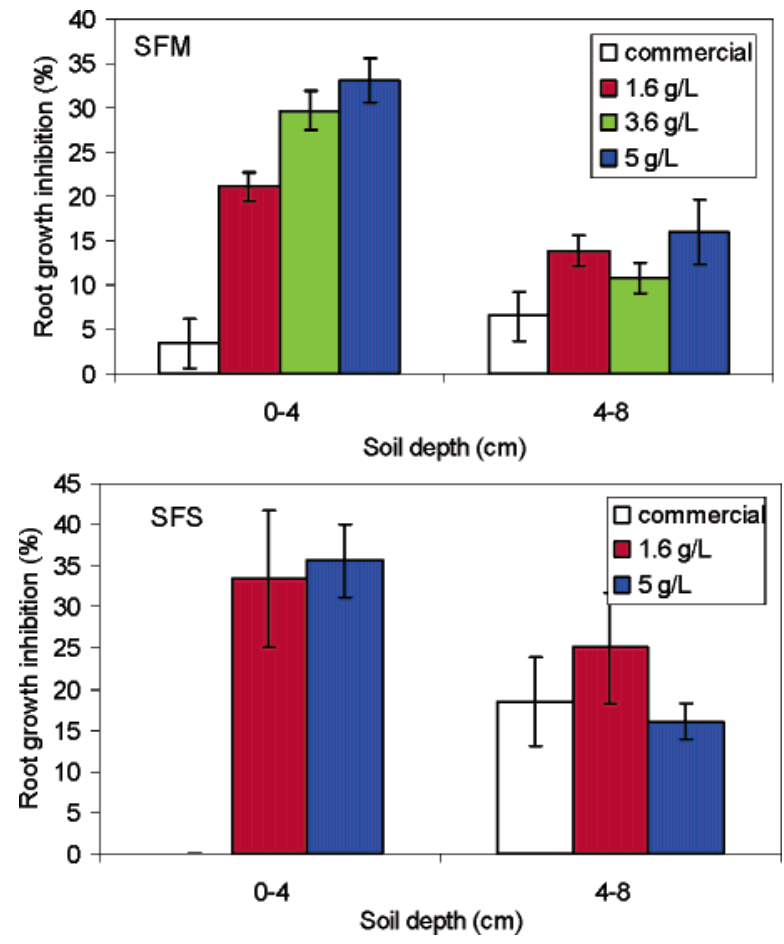

FIGURE 6. Root grow th inhibition of a test plant (Sorghum) as a function of the depth of the soil columns sprayed with the commercial formulations and clay-liposome formulations of SFM and SFS. The rate used was $420 \mathrm{~g}$ a.i. ha ${ }^{-1}$.

the commercial formulation and that of the $5 \mathrm{~g} / \mathrm{L}$ formulation. In this case, a more realistic rate under field conditions was chosen for SFS ( $35 \mathrm{~g}$ a.i. ha ${ }^{-1}$ ), and only 1 pore volume was added. Because of the low SFS dose used, it was not possible to detect any amount of the herbicide in the leachates. However, bioassays are very sensitive for exhibiting responses to very small amounts of residues (35). The inhibition percentages in the top layer soil were $6.1 \pm 3.3 \%$ and 16.7 $\pm 2.3 \%$ for the commercial and the $5 \mathrm{~g} / \mathrm{L}$ formulations, respectively.

In general, slow release formulations should be designed to obtain a compromise between the reduction in leaching and the herbicidal activity in the top soil layer. The clayliposome formulations fulfill both of these requirements, since the amount of herbicide leached was reduced severalfold and the biological activity was enhanced in the upper layer of thesoil, which is of primeconcern for long-run weedcontrol. Therefore, the rates of application of the new liposome-clay formulations can be lower than those of the commercial formulations, which amounts to economical and environmental advantages.

A comparison of our results with those obtained with the developed micelle-clay system (16) indicates that the liposome-clay system is similar or somewhat better in reducing the leached amounts of SFM. However, the liposome-clay system has an advantage that it may be also employed for encapsulating hydrophilic herbicides to yield their slow release.

\section{Acknowledgments}

The authors acknowledge M. F. Hidalgo for technical assistanceand Dr. Justo for help in the XRD section; financial funding by the Spanish Ministry of Science and Technology (Projects REN2000-1540 and AGL2002-00993); The Hebrew University of Jerusalem through a grant from the Wolfson Foundation for Scientific Research, Matching-Bergman; and Grant G-641-106.8/ 1999 from the German-Israeli Foundation for Research and Development. T. Undabeytia also acknowledges the Spanish government for a Ramon y Cajal research contract.

\section{Supporting Information Available}

Speciation in solution and adsorption results on montmorillonite of DDAB liposomes containing SFS (Table S1). This material is available free of charge via the Internet at http:/ / pubs.acs.org.

\section{Literature Cited}

(1) Weber, J.; Mahnken, G.; Swain, L. Soil Sci. 1999, 164, 417.

(2) Enderlein, R. E. Water Sci. Technol. 1995, 31, 1

(3) Barbash, J.; Thelin, G.; Kolpin, D.; Gilliom, R. J. Environ. Qual. 2001, 30, 831.

(4) Wijnands, F. G. European J. Agron. 1997, 7, 251

(5) El-Nahhal, Y.; Undabeytia, T.; Polubesova, T.; Mishael, Y.; Nir, S.; Rubin, B. Appl. Clay Sci. 2001, 18, 309.

(6) Akelah, A. Mater. Sci. Eng.: C 1996, 4, 83.

(7) Hu, X. P.; Shasha, B. S.; McGuire, M. R.; Prokopy, R. J. J. Controlled Release 1998, 50, 275.

(8) Zhu, Z.; Zhuo, R. Eur. Polym. J. 2001, 37, 1913.

(9) Fernández-Urrusuno, R.; Ginés, J. M.; Morillo, E. J. Microencapsulation 2000, 17, 331.

(10) Villafranca-Sánchez, M.; González-Pradas, E.; Fernández-Pérez, M.; Martínez-López, F.; Flores-Céspedes, F.; Ureña-Amate, M. D. Pest Manag. Sci. 2000, 56, 749.

(11) Pérez-Martínez, J. I.; Ginés, J. M.; Morillo, E.; GonzálezRodríguez, M. L.; Moyano, J. R. Environ. Technol. 2000, 21, 209.

(12) Sparks, R. E.; Jacobs, I. C. In Controlled-release delivery systems for pesticides; Scher, H. B., Ed.; Marcel Dekker: New York, 1999; pp 3-29.

(13) Stork, P.; Hannah, M. C. Weed Res. 1996, 36, 271.

(14) Ahrens, H. W. HerbicideHandbook, 7 ed.; Weed Science Society of America: IL, 1994.

(15) Sternberg, B. In LiposomeTechnology; Gregoriadis, G., Ed.; CRC Press: Boca Raton, FL, 1993; pp 363-383.

(16) Mishael, Y. G.; Undabeytia, T.; Rabinovitz, O.; Rubin, B.; Nir, S. J. Agric. Food Chem. 2002, 50, 2864.

(17) Svitova, T. F.; Smirnova, Y. P.; Pisarev, S. A.; Berezina, N. A. Colloids Surf. A: Physicochem. Eng. Aspects 1995, 98, 107.

(18) Caria, A.; Regev, O.; Khan, A. J. Colloid Interface Sci. 1998, 200, 19.

(19) Mishael, Y. G.; Undabeytia, T.; Rytwo, G.; PapahadjpoulosSternberg, B.; Rubin, B.; Nir, S. J. Agric. Food Chem. 2002, 50, 2856.

(20) Lagaly, G. Characterization of clays by organic compounds. Clay Miner. 1981, 16, 1.

(21) Tahani, A.; Karroua, M.; Van Damme, H.; Levitz, P.; Bergaya, F. J. Colloid Interface Sci. 1999, 216, 242.

(22) Dubois, M.; Zemb, Th. Langmuir 1991, 7, 1352.

(23) Jaynes, W. F.; Vance, G. F. Soil Sci. Soc. Am. J. 1996, 60, 1742.

(24) Egawa, H.; Furusawa, K. Langmuir 1999, 15, 1660.

(25) Regev, O.; Khan, A. Prog. Colloid Polym. Sci. 1994, 97, 298.

(26) Manne, S.; Gaub, H. E. Science 1995, 270, 1480.

(27) Manne, S.; Schaffer, T. E.; Huo, Q.; Hansma, P. K.; Morse, D. E.; Stucky, G. D.; Aksay, I. A. Langmuir 1997, 13, 6382.

(28) Nir, S.; Peled, R.; Lee, K. D. Colloids Surf. 1994, 89, 45

(29) Nir, S.; Undabeytia, T.; Marcovich, Y.-D.; El-Nahhal, Y.; Polubesova, T.; Serban, C.; Rytwo, G.; Lagaly, G.; Rubin, B. Environ Sci. Technol. 2000, 34, 1269.

(30) Naidu, R.; Bolan, N. S.; Kookana, R. S.; Tiller, K. G. J. Soil Sci. 1994, 45, 419.

(31) Nir, S.; Hirsch, D.; Navrot, J.; Banin, A. Soil Sci. Soc. Am. J. 1986, 50, 40.

(32) Polubesova, T.; Rytwo, G.; Nir, S.; Serban, C.; Margulies, L. Clays Clay Miner. 1997, 45, 834.

(33) Xu, S.; Boyd, S. A. Environ. Sci, Technol. 1995, 29, 312

(34) Sarmah, A. K.; Kookana, R. S.; Alston, A. M. Aust. J. Agric. Res. 1998, 49, 775.

(35) Vicari, A.; Dinelli, G.; Catizone, P. Agrochimica 1998, 52, 273.

Received for review April 15, 2003. Revised manuscript re ceived July 18, 2003. Accepted July 24, 2003.

ES0343508 